ago. Someone is sure to tell the story-one that has been told to our knowledge for more than 30 years - of the ECT machine that broke down or was not connected properly, "and the patients did just as well." Throw in an angry $\mathrm{MP}$, a lawyer or two, some confusing references to compulsory treatment under the Mental Health Act, some ancient film of straight ECT from the days of Cerletti and Bini-hardly more frightening than the very poorly modified treatment shown in some programmes-and the picture is almost complete.

Few experienced psychiatrists would deny that we need more precise information about the indications for ECT, just as we need more information about other treatments, such as lithium and antidepressant drugs, that have been shown empirically to work well for many patients. And few would deny that ECT, perhaps because it often works wonderfully well, has often been used indiscriminately. But surely the consensus and the uniformity of practice throughout the United Kingdom that have emerged from 30 years of experience confirm its place as the most consistently effective treatment of severe depression that is available to us. The distortions of the media, reinforced by the malign influence of bodie such as the Citizen's Commission on Human Rights that have long campaigned agains psychiatry in all its aspects, have produced so much dread and suspicion that we have moved very quickly to a point where psychiatrists are under great pressure to withhold what is often a life-saving treatment, and where patients who could benefit are too afraid to seek help of any sort.

Psychiatrists have always tended to regard attacks on themselves and their profession as manifestations of neurotic reaction, the product of society's too heavily defended ego, and have responded with the essentially therapeutic bland tolerance appropriate to any negative transference. To some extent this may be good for society and good for psychiatrists; but it would be tragic if it obscured the fact that in this instance the real victims of such irrational hostility are the most vulnerable members of society.

We are not alone in our anxiety, and it is good to learn from Dr Haslam's letter (13 August, p 455) that the Society of Clinica Psychiatrists is shortly to publish a report on public relations in psychiatry. So far as we are aware, only the Guardian has made a reference, somewhat lukewarm, to the Royal College of Psychiatrists' memorandum on the use of electroconvulsive therapy which appeared in the British fournal of Psychiatry in September the long delay before its publication and its obvious lack of impact suggest that psychiatrists have much to learn about public relations.

If we shrink from our responsibilities now, when and where do we make our stand? It would be a salutary exercise for anyone who, for whatever motive, seeks to criticise ECT to read Aubrey Lewis's classic 1934 study of melancholia. No doubt enterprising journalists will soon discover that lithium sometimes causes myxoedema and tricyclic antidepressants can impair cardiac conduction; and then it would be back to 1934, when melancholia has to run its natural course, but without the resources to hospitalise the patient for 3 years. Perhaps by then our patients will fight our battles for us and we can watch the banners of CURE-Campaign Urging the Restoration of Electroplexy-from the sidelines. But that is a long way off and by then many thousands of patients who could have been effectively treated will have suffered the most terrible of all human afflictions. And many-perhaps the more fortunate-will have died.

$\begin{array}{ll}\text { J F ANDERSON } & \text { P SETHI } \\ \text { E J MACDONALD } & \text { S F LINDSAY } \\ \text { A MORRISON } & \text { A M MACLEOD } \\ \text { K M ARMIT } & \text { I R SHERRET } \\ \text { D M MACGREGOR } & \end{array}$

Medical Committee

Stratheden Hospital,

Cupar,

\section{The debasement of consent}

SIR,-You published (10 September, p 713), under the heading "Guidelines on ECT," a summary of the memorandum on the use of electroconvulsive therapy issued by the Royal College of Psychiatrists. ${ }^{1}$ In it you allude to two recommendations, the implications of which extend beyond psychiatry to medicine as a whole

(1) "Consent ... should be obtained from formal [that is, detained] patients. If ECT is thought essential and the patient is unwilling section $26 \ldots$ should be applied and... two consultant opinions obtained"-and then (it is clearly inferred) the treatment given al the same.

(2) “. . relatives cannot give legal consent. Nevertheless ... obtaining relatives' consent is strongly advised"-but if they refuse it and ECT is deemed essential (again the inference is clear) it should still be given.

I am in no doubt but the college's advice was given with Mind, and especially its special report $A$ Human Condition ${ }^{2}$ and possibly Jacob ${ }^{3}$ also, hanging menacingly over its head. I have heard it rumoured that the three defence bodies concur. Yet I am sure all three (or six) are wrong, and dangerously so for the proper practice of medicine. Consent should never be asked unless the decision of him asked is to be honoured. To say to patient or relative, "I seek your consent, but I shall act regardless of it," debases the value of the coin of consent : a coin of value too priceless to be debased without fundamental erosion of the standard of human discourse. The procedure smacks, furthermore, of subtly cynical type of Hitlerism. May we please have the courage to take decisions where necessary (for the life or health of our patients) fully upon ourselves and not make a charade of shoving them off on to those unqualified to take them?

A postscript: I disagree with the "legal advice" that section 25 of the Mental Health Act is insufficient for ECT and have obtained a lawyer's corroboration of my disagreement.

Oxford

Seymour SPENSER

'Royal College of Psychiatrists, British fournal of Psychiatry, 1977, 131, 261 .

Gostin, L O, Mind Special Report, pp 121-2, October ${ }^{3}$ Jacob, J, The Modern Law Review, 1976, 39, 17.

\section{ECT in underdeveloped countries}

SIR,-As a member of the Special Committee on Electric Convulsion Therapy (ECT) of the Royal College of Psychiatrists I would like to make a few points which arise from the letter of Wendy Farrant ( 1 October, p 895).

The implication is that colleagues recommending ECT are not adequate in the field of general medical practice to administer the appropriate medication themselves. About 25 years ago I drew attention in these columns to the availability of a short-acting muscle relaxant covered by intravenous anaesthesia. At a meeting some months later of the (then) Royal Medico-Psychological Association I sought, and obtained, agreement that until anaesthetists had acquired the appropriate knowledge and skills (not yet disseminated) it was acceptable for a psychiatrist to administer the anaesthetic and relaxant himself. It was not long before the collaboration of anaesthetists became routine, but this is a professional and ethical safeguard-dare I say not an essential ? Is there any reason to think that there are doctors anywhere who could not do this quite simple job?

Literacy and written consent in developing countries obviously present a different problem, but verified oral consent with the aid of an interpreter (which is what most of my colleagues and I obtain for foreign patients) could go some way towards resolving it.

Having used chemical, electrical, and inhalant convulsive techniques for over 30 years, less frequently in favour of antidepressant medication since about 1957, I would encourage doctors overseas (or anywhere) to take a good look at the indications for ECT. I am still satisfied that it is the treatment of immediate choice for some patients-but only for some.

Perhaps I may add a personal note. In thousands of treatments of general hospital inand out-patients and of private patients at home, in nursing homes, and here I have had two operation mishaps, both dental, before I decided not to remove incomplete dentures supporting spaced teeth. (There is no masseter jerk with flurethyl induction.

L RosE

London W1

\section{Dispute in Malta}

SIR,-With reference to the appeal launched by the British Medical fournal (10 September p 708), allow me to draw your readers' attention to the plight of the Maltese medical profession. The current dispute between the Maltese Government and the Medical Association of Malta (MAM) arose out of disagreement over new legislation affecting newly qualified doctors and the powers of the Medical Council. In protest, the MAM directed its members to take limited action involving outpatient clinics and non-urgent surgical operations, while continuing to provide the necessary cover for emergencies.

The Maltese Government reacted by ordering a lock-out of doctors and specialists from all State hospitals and by importing foreign doctors from Libya, Czechoslovakia, Pakistan, and the Palestine Liberation Organisation to man emergency hospital services. Within a few days punitive legislation was rushed through parliament prohibiting the Maltese doctors and specialists from practising in private hospitals. Further legislation culminated in their dismissal not only from their government posts but also, in some cases, from their university appointments. The latter included the professors of medicine, surgery, and obstetrics and gynaecology.

The lock-out affected local as well as British external examiners, with the result that final year medical students who were due to qualify last June could not complete their 